\title{
Asthma from birth to age 23: incidence and relation to prior and concurrent atopic disease
}

\author{
H R Anderson, A C Pottier, D P Strachan
}

\begin{abstract}
Background Few studies present prospective data on the incidence of asthma. Its associations with sex and with prior and concurrent hay fever and eczema were examined in a nationally representative sample followed from birth to 23 years of age (British 1958 birth cohort).

Methods Reports of asthma or wheezy bronchitis, hay fever and eczema were obtained by interview of parents of children at ages 7,11 , and 16 years, and of cohort members at age 23 years. Linked data from all four interviews were available on 7225 subjects $(43 \%$ of the original birth cohort).
\end{abstract}

Results The cumulative incidence of asthma or wheezy bronchitis was $18 \cdot 2 \%$, $21 \cdot 8 \%, 24 \cdot 5 \%$, and $28.6 \%$ by the ages of 7 , 11,16 , and 23 years respectively. Over the four incidence periods examined ( 0 to 7 years, 8 to 11 years, 12 to 16 years, 17 to 23 years) the average annual incidence of new cases was $2.6 \%, 1.1 \%, 0.71 \%$, and $0.76 \%$ respectively. The male:female incidence ratio rose from 1.23 in the 0 to 7 year period to 1.48 at 12 to 16 years but had reversed to 0.59 at 17 to 23 years. A prior report of hay fever or eczema each increased the subsequent incidence of asthma or wheezy bronchitis by a factor of 1.7 to 2.0 independently of sex. This effect of prior atopic illness, however, was largely explained by the strong independent association of incidence of asthma and wheezy bronchitis with atopic disease at the end of each incidence period (odds ratios 2.0 to 2.5 per atopic condition, $\mathbf{p}<0.01$ ).

Conclusions Gender differences in the incidence of asthma or wheezy bronchitis vary with age and are not explained by atopy. The incidence of asthma or wheezy bronchitis can be predicted from a clinical history of hay fever or eczema but is more strongly associated with the presence of atopic disease at the time of onset.

Department of Public Health Sciences, $\mathbf{S t}$ George's Hospital Medical School, London SW17 ORE H R Anderson A C Pottier

D P Strachan

Reprint requests to: Professor Anderson

Accepted 15 February 1992
The epidemiology of asthma would be better about factors affecting incidence-that is, the rate at which new cases of asthma appear in the population. Direct measurement of incidence is difficult because it requires regular follow up of large cohorts of non-asthmatic individuals over long periods. Most of our present knowledge is based on period prevalence-that is, the proportion of the population with a history of asthma over a prior period, but this is influenced not only by incidence but also by prognosis. Prevalence studies, being cross sectional, are subject to recall bias and give rise to difficulties in separating cause and effect.

The National Child Development Study has followed a British national cohort of over 17414 children born during one week in March 1958. Data are available for the perinatal period and at ages $7,11,16$, and 23 years. It provides a rare opportunity to describe the incidence of asthma in the early years of life in a large and representative sample.

We have reported previously some of the findings relating to asthma up to the age of 16 years. ${ }^{1}$ The present paper extends this analysis to the age of 23 years and for the first time incorporates a multiple regression analysis to examine the independent effects of three important predictors of incidence: sex, hay fever, and eczema.

\section{Methods}

Data for the appropriate variables were obtained from the Economic and Social Research Council Data Archive at Essex University and additional variables were extracted from the microfilm records by the authors. At each sweep, data about asthma or wheezing illness were available as follows:

Sweep 1. At 7 years of age the parents of the subjects were asked whether their child had ever had "attacks of asthma," and the same question was repeated for "bronchitis with wheezing." For each question, the number of attacks in the past 12 months was recorded.

Sweep 2. At 11 years of age the parents were asked whether their child had ever had attacks of "asthma," "wheezing bronchitis" or "neither of these," and if so the frequency in the past 12 months.

Sweep 3. At 16 years of age the parents were asked whether their child had "ever had an attack of asthma or wheezy bronchitis," and if so the frequency in the past 12 months.

Sweep 4. At 23 years of age the subject himself or herself was asked, "Have you had an attack of asthma or wheezy bronchitis since your 16th birthday," and as before the occurrence of attacks in the past 12 months was recorded.

Because at 16 and 23 years of age the questions did not separate asthma from wheezy bronchitis and because there is a reasonable clinical and pathological justifica- 
tion for combining them ${ }^{2}$ the two entities were combined at 7 and 11 years of age. At the 7 year follow up a history of eczematous rashes and hay fever or recurrent sneezing attacks since birth was recorded. In subsequent sweeps respondents were asked about eczema and hay fever or allergic rhinitis occurring in the past 12 months.

The number of surviving children entering the National Child Development Study from the National Perinatal Study was 16883 . Data relating to asthma or wheezy bronchitis were available for $14548(86 \%), 13504(80 \%)$, $11392(67 \%)$, and $12521(74 \%)$ subjects for sweeps 1 to 4 respectively. This analysis is confined to those for whom complete data are available up to a given age. For the description of prevalence and incidence we have used a fully linked data set, comprising 7225 subjects for whom data are available for each sweep ( $43 \%$ of cohort, $50 \%$ of those seen at 7 years of age).

For the analysis of factors associated with the incidence of asthma, three study periods were identified: ages 8 to 11 years, 12 to 16 years, and 17 to 23 years. Persons with a history of asthma or wheezy bronchitis before the start of each period were identified, data from all relevant prior sweeps being used, and were excluded from each analysis. Among the remainder of the cohort, incident cases were identified from reports of asthma or wheezy bronchitis "ever" obtained at the end of each study period.

The independent effects of sex, hay fever, and eczema on the incidence of asthma or wheezy bronchitis were examined for each study period. Hay fever and eczema were categorised as follows: reported at any of the relevant sweeps up to the beginning of the study period (prior atopy) and reported in the past year at the end of the study period. For certain analyses prior atopy was further subdivided according to whether hay fever or eczema was reported in the past year at the start of the study period.

Logistic regression models were fitted by using the LOGIST procedure in SAS $^{3}$ with the incidence of asthma or wheezy bronchitis as the outcome variable and sex and atopic diseases as explanatory variables. Models were compared by likelihood ratio $\chi^{2}$ statistics to derive a simplified but valid description of the relationship between atopic diseases and the incidence of asthma or wheezy bronchitis.

\section{Results}

PREVALENCE

The reported prevalence of asthma or wheezy bronchitis "ever" and in the past 12 months at each sweep is shown in table 1. The annual period prevalence was highest at age 7 years $(8.1 \%)$ but thereafter remained fairly constant at around 3 to $4 \%$. Prevalence was higher in males up to 16 years of age but at age 23 years the prevalence ratio had reversed with a substantially higher prevalence in females. The 12 month period prevalences of asthma or wheezy bronchitis among all subjects interviewed at each sweep (irrespective of whether they were part of the linked cohort) were $8.1 \%$ (1184/ 14 548), 4.9\% (664/13 504), 3.8\% (427/11 392) and $4.3 \%(540 / 12521)$ at ages $7,11,16$, and 23 years respectively.

\section{CUMULATIVE INCIDENCE}

The cumulative incidence, calculated on the basis of all prior information, is shown in table 2. These incidence rates are much higher than those obtained retrospectively, which, paradoxically, declined with age (table 1). The proportion of the cohort who had experienced asthma or wheezing by 23 years of age was $28.6 \%$. The cumulative incidence was only slightly higher for males $(30 \cdot 1 \%)$ than for females $(27 \cdot 1 \%)$.

The incidence between each sweep is shown in table 3. The average annual incidence was highest in the 0 to 7 year period $(2.6 \%$ per year $)$ but levelled out at about $0.7 \%$ per year from 12 to 23 years. The male:female ratio increased from 1.23 at 7 years of age to 1.31 at 11 years and 1.5 at 16 years, and then showed a marked reversal to 0.59 . In females the incidence between 17 and 23 years of age was almost $1 \%$ per year.

\section{EFFECT OF ATOPY PRIOR TO THE INCIDENCE PERIOD}

The multiple regression analyses shown in tables 4,5 and 6 focused on three incidence periods ( 8 to 11 years, 12 to 16 years and 17 to 23 years) on the basis of all available data up to the start of each study period; hence the denominators differ from those in table 3 for the first two incidence periods. The numbers and incidence values used in this analysis are shown in table 4. A higher incidence among boys is seen until 16 years of age, when the sex ratio reverses. Table 4 also shows the incidence of asthma or wheezy bronchitis for males and

Table 1 Percentage prevalence of asthma or wheezing at each sweep in subjects with data at each sweep (linked data set: 3583 males, 3642 females)

\begin{tabular}{|c|c|c|c|c|c|}
\hline & & Age 7 & Age 11 & Age 16 & Age 23* \\
\hline $\begin{array}{l}\text { Report of asthma or wheezing ever } \\
\text { (reported lifetime prevalence) }\end{array}$ & $\begin{array}{l}\text { Males } \\
\text { Females } \\
\text { Total } \\
\text { M:F ratio }\end{array}$ & $\begin{array}{l}20 \cdot 0(716) \\
16 \cdot 3(595) \\
18 \cdot 2(1311) \\
1 \cdot 2\end{array}$ & $\begin{array}{l}13 \cdot 7(492) \\
10 \cdot 4(377) \\
12 \cdot 0(869) \\
1 \cdot 3\end{array}$ & $\begin{array}{r}13 \cdot 7(490) \\
9 \cdot 3(337) \\
11.5(827) \\
1.5\end{array}$ & \\
\hline $\begin{array}{l}\text { Report of asthma or wheezing in } 12 \text { months } \\
\text { prior to interview } \\
\text { (12 month period prevalence) }\end{array}$ & $\begin{array}{l}\text { Males } \\
\text { Females } \\
\text { Total } \\
\text { M:F ratio }\end{array}$ & $\begin{array}{l}8 \cdot 9(320) \\
7 \cdot 2(263) \\
8 \cdot 1(583) \\
1 \cdot 2\end{array}$ & $\begin{array}{l}5 \cdot 4(192) \\
3 \cdot 8(137) \\
4 \cdot 6(329) \\
1.4\end{array}$ & $\begin{array}{l}3 \cdot 9(138) \\
2 \cdot 8(102) \\
3 \cdot 3(240) \\
1 \cdot 4\end{array}$ & $\begin{array}{l}3 \cdot 2(116) \\
4 \cdot 7(172) \\
4 \cdot 0(288) \\
0 \cdot 68\end{array}$ \\
\hline
\end{tabular}

*At age 23 the question referred only to asthma or wheezing since the 16th birthday. Number of prevalent cases in parentheses. 
Table 2 Percentage cumulative incidence of asthma or wheezing to age 23 years in subjects with data at each sweep (linked data set: 3583 males, 3642 females)

\begin{tabular}{lcccc}
\hline & Age 0-7 & Age 0-11 & Age 0-16 & Age 0-23 \\
\hline Males & $20.0(716)$ & $24.0(860)$ & $27 \cdot 2(976)$ & $30 \cdot 1(1078)$ \\
Females & $16.3(595)$ & $19.6(712)$ & $21.9(797)$ & $27 \cdot 1(986)$ \\
Total & $18 \cdot 2(1311)$ & $21.8(1572)$ & $24.5(1773)$ & $28.6(2064)$ \\
M:F ratio & 1.23 & 1.2 & 1.24 & $1 \cdot 11$ \\
\hline
\end{tabular}

Number of incident cases in parentheses.

females by the history of eczema and hay fever up to and including the start of the study period. After adjustment for sex, prior eczema and prior hay fever predicted incident wheeze during all three study periods. In subjects with a prior history of only one atopic disease, the relative risks associated with eczema and hay fever did not differ significantly from each other $\left(\chi^{2}=0.35,0.87\right.$, and $2 \cdot 20$ for ages 8 to 11 years, 12 to 16 years, and 17 to 23 years respectively, $\mathrm{df}=1$ in each case). Subjects with a prior history of both atopic diseases were at high risk of subsequent asthma, but this was not significantly greater than that predicted from the combined effect of prior eczema and prior hay fever-that is, the product of the relative risk associated with each prior atopic condition $\left(\chi^{2}=0.74,1.81\right.$, and 0.18 respectively, $\mathrm{df}=1)$. The effects of prior atopic disease upon incident asthma in each study period could therefore be described simply but adequately by a single parameter, the odds ratio (relative risk) per prior atopic condition. These odds ratios (with $95 \%$ confidence limits) are shown in table 5 .
The effect of prior atopy did not differ significantly between the sexes $\left(\chi^{2}\right.$ for interaction $=0.63,0.53$, and 0.08 at ages 8 to 11 years, 12 to 16 years, 17 to 23 years respectively, $\mathrm{df}=1$ ). When adjustment was made for the number of previous atopic diseases, a report of either eczema or hay fever in the past year at the start of the incidence period was not a significant predictor of subsequent asthma or wheeze from age 8 to 11 years (odds ratio $=1 \cdot 28,95 \%$ confidence interval $0.78-2 \cdot 08, \chi^{2}=0.94$, df $=$ 1 ), or from age 12 to 16 years (odds ratio = $1 \cdot 06,95 \%$ confidence interval $0 \cdot 61-1 \cdot 84, \chi^{2}=$ 0.00 , $\mathrm{df}=1$ ), although between ages of 17 and 23 years it was of borderline significance (odds ratio $=1.59,95 \%$ confidence interval 0.98 $2.58, \chi^{2}=3.53 \mathrm{df}=1$ ).

\section{EFFECT OF ATOPY AT THE END OF THE INCIDENCE} PERIOD

In contrast, when adjusted for the number of atopic diseases reported up to and including the start of the study period, a report of eczema or hay fever in the past year at the end of the study period was strongly associated with the incidence of asthma or wheezy bronchitis $\left(\chi^{2}=24.33,28.03\right.$, and 33.38 for ages 8 to 11 years, 12 to 16 years and 17 to 23 years respectively, $\mathrm{df}=1$ ). We therefore explored the relationship between the incidence of asthma or wheezing and the number of atopic diseases at the end of each study period in a similar series of models to those described for prior atopy.

As with prior atopy, both eczema and hay fever were associated independently with

Table 3 Incidence of new asthma or wheezing illness between sweeps in subjects with data at each sweep (linked data set), excluding those who had previously developed these symptoms

\begin{tabular}{|c|c|c|c|c|c|c|c|c|c|c|c|c|c|c|c|c|}
\hline & \multicolumn{4}{|c|}{ Age 0-7 } & \multicolumn{4}{|c|}{ Age 8-11 } & \multicolumn{4}{|c|}{ Age 12-16 } & \multicolumn{4}{|c|}{ Age 17-23 } \\
\hline & $\%$ & No & Population & $\% /$ year & $\%$ & No & Population & $\% /$ year & $\%$ & No & Population & $\% /$ year & $\%$ & No & Population & $\% /$ year \\
\hline $\begin{array}{l}\text { Males } \\
\text { Females } \\
\text { Total } \\
\text { M:F ratio }\end{array}$ & $\begin{array}{l}20 \cdot 0 \\
16 \cdot 3 \\
18 \cdot 2 \\
1.23\end{array}$ & $\begin{array}{r}716 \\
595 \\
1311\end{array}$ & $\begin{array}{l}3583 \\
3642 \\
7225\end{array}$ & $\begin{array}{l}2 \cdot 9 \\
2 \cdot 3 \\
2 \cdot 6\end{array}$ & $\begin{array}{l}5 \cdot 0 \\
3 \cdot 8 \\
4 \cdot 4 \\
1 \cdot 31\end{array}$ & $\begin{array}{l}144 \\
117 \\
261\end{array}$ & $\begin{array}{l}2867 \\
3047 \\
5914\end{array}$ & $\begin{array}{l}1 \cdot 3 \\
1 \cdot 0 \\
1 \cdot 1\end{array}$ & $\begin{array}{l}4 \cdot 3 \\
2 \cdot 9 \\
3 \cdot 6 \\
1 \cdot 47\end{array}$ & $\begin{array}{r}116 \\
85 \\
201\end{array}$ & $\begin{array}{l}2723 \\
2930 \\
5653\end{array}$ & $\begin{array}{l}0.85 \\
0.58 \\
0.71\end{array}$ & $\begin{array}{l}3 \cdot 9 \\
6 \cdot 6 \\
5 \cdot 3 \\
0 \cdot 59\end{array}$ & $\begin{array}{l}102 \\
189 \\
291\end{array}$ & $\begin{array}{l}2607 \\
2845 \\
5452\end{array}$ & $\begin{array}{l}0.56 \\
0.94 \\
0.76\end{array}$ \\
\hline
\end{tabular}

Table 4 Incidence of asthma or wheezy bronchitis during each study period by sex and history of hay fever or eczema up to the start of each study period on the basis of all available information

\begin{tabular}{|c|c|c|c|c|c|c|c|c|c|c|c|}
\hline \multirow{2}{*}{$\begin{array}{l}\text { Prior } \\
\text { hay fever }\end{array}$} & \multirow{2}{*}{$\begin{array}{l}\text { Prior } \\
\text { eczema }\end{array}$} & \multirow[b]{2}{*}{ Sex } & \multicolumn{3}{|c|}{ Age 8-11 } & \multicolumn{3}{|c|}{ Age 12-16 } & \multicolumn{3}{|c|}{ Age 17-23 } \\
\hline & & & $\%$ & No & Population & $\%$ & No & Population & $\%$ & No & Population \\
\hline No & No & $\begin{array}{l}\text { Male } \\
\text { Female } \\
\text { Both }\end{array}$ & $\begin{array}{l}4 \cdot 7 \\
3 \cdot 7 \\
4 \cdot 2\end{array}$ & $\begin{array}{l}205 \\
161 \\
366\end{array}$ & $\begin{array}{l}4343 \\
4363 \\
8706\end{array}$ & $\begin{array}{l}3 \cdot 6 \\
2 \cdot 7 \\
3 \cdot 2\end{array}$ & $\begin{array}{r}97 \\
76 \\
173\end{array}$ & $\begin{array}{l}2693 \\
2790 \\
5483\end{array}$ & $\begin{array}{l}3 \cdot 3 \\
5 \cdot 9 \\
4 \cdot 6\end{array}$ & $\begin{array}{r}63 \\
127 \\
190\end{array}$ & $\begin{array}{l}1936 \\
2157 \\
4093\end{array}$ \\
\hline No & Yes & $\begin{array}{l}\text { Male } \\
\text { Female } \\
\text { Both }\end{array}$ & $\begin{array}{l}7.9 \\
5 \cdot 0 \\
6 \cdot 3\end{array}$ & $\begin{array}{l}19 \\
15 \\
34\end{array}$ & $\begin{array}{l}242 \\
298 \\
540\end{array}$ & $\begin{array}{l}5 \cdot 6 \\
3 \cdot 4 \\
4 \cdot 4\end{array}$ & $\begin{array}{r}10 \\
8 \\
18\end{array}$ & $\begin{array}{l}178 \\
234 \\
412\end{array}$ & $\begin{array}{l}5 \cdot 8 \\
6 \cdot 0 \\
5 \cdot 9\end{array}$ & $\begin{array}{r}9 \\
12 \\
21\end{array}$ & $\begin{array}{l}154 \\
200 \\
354\end{array}$ \\
\hline Yes & No & $\begin{array}{l}\text { Male } \\
\text { Female } \\
\text { Both }\end{array}$ & $\begin{array}{l}8 \cdot 5 \\
6 \cdot 0 \\
7 \cdot 3\end{array}$ & $\begin{array}{r}14 \\
9 \\
23\end{array}$ & $\begin{array}{l}165 \\
150 \\
315\end{array}$ & $\begin{array}{l}8 \cdot 5 \\
3 \cdot 4 \\
6 \cdot 2\end{array}$ & $\begin{array}{r}21 \\
7 \\
28\end{array}$ & $\begin{array}{l}248 \\
205 \\
453\end{array}$ & $\begin{array}{r}6 \cdot 0 \\
10 \cdot 7 \\
8 \cdot 3\end{array}$ & $\begin{array}{l}18 \\
29 \\
47\end{array}$ & $\begin{array}{l}298 \\
271 \\
569\end{array}$ \\
\hline Yes & Yes & $\begin{array}{l}\text { Male } \\
\text { Female } \\
\text { Both }\end{array}$ & $\begin{array}{l}19 \cdot 2 \\
11 \cdot 1 \\
15 \cdot 1\end{array}$ & $\begin{array}{l}5 \\
3 \\
8\end{array}$ & $\begin{array}{l}26 \\
27 \\
53\end{array}$ & $\begin{array}{l}15 \cdot 6 \\
14 \cdot 3 \\
14 \cdot 9\end{array}$ & $\begin{array}{r}7 \\
6 \\
13\end{array}$ & $\begin{array}{l}45 \\
42 \\
87\end{array}$ & $\begin{array}{r}4 \cdot 4 \\
18 \cdot 6 \\
12 \cdot 5\end{array}$ & $\begin{array}{r}2 \\
11 \\
13\end{array}$ & $\begin{array}{r}45 \\
59 \\
104\end{array}$ \\
\hline All subjects & & $\begin{array}{l}\text { Male } \\
\text { Female } \\
\text { Both }\end{array}$ & $\begin{array}{l}5 \cdot 1 \\
3 \cdot 9 \\
4 \cdot 5\end{array}$ & $\begin{array}{l}243 \\
188 \\
431\end{array}$ & $\begin{array}{l}4776 \\
4838 \\
9614\end{array}$ & $\begin{array}{l}4 \cdot 3 \\
3 \cdot 0 \\
3 \cdot 6\end{array}$ & $\begin{array}{r}135 \\
97 \\
232\end{array}$ & $\begin{array}{l}3164 \\
3271 \\
6435\end{array}$ & $\begin{array}{l}3 \cdot 8 \\
6 \cdot 7 \\
5 \cdot 3\end{array}$ & $\begin{array}{r}92 \\
179 \\
271\end{array}$ & $\begin{array}{l}2433 \\
2687 \\
5120\end{array}$ \\
\hline
\end{tabular}


Table 5 Odds ratio estimates derived from four alternative logistic regression models of asthma incidence in relation to sex, prior atopic conditions and atopic diseases reported in the past year at the end of each study period (restricted to data presented in tables 4 and 6)

\begin{tabular}{|c|c|c|c|c|}
\hline & \multirow[b]{2}{*}{ Variables in model } & \multicolumn{3}{|c|}{$\begin{array}{l}\text { Odds ratio ( } 95 \% \text { confidence interval) for incidence of asthma or } \\
\text { wheezy bronchitis: }\end{array}$} \\
\hline & & Age 8-11 & Age $12-16$ & Age 17-23 \\
\hline 1 & Sex (male $v$ female) ${ }^{\star}$ & $1.33(1.09-1.61)$ & $1.46(1.12-1.92)$ & $0.55(0.43-0.71)$ \\
\hline 2 & $\begin{array}{l}\text { Sex (male } v \text { female) } \\
\text { Prior atopy (per atopic condition) }\end{array}$ & $\begin{array}{l}1.35(1 \cdot 10-1 \cdot 61) \\
1.76(1 \cdot 38-2 \cdot 23)\end{array}$ & $\begin{array}{l}1.45(1 \cdot 11-1.89) \\
2.00(1.57-2 \cdot 55)\end{array}$ & $\begin{array}{l}0.55(0.43-0.71) \\
1.67(1.34-2.08)\end{array}$ \\
\hline 3 & $\begin{array}{l}\text { Sex (male } v \text { female) } \\
\text { Atopy at end of period (per atopic condition) }\end{array}$ & $\begin{array}{l}1.32(1.09-1 \cdot 61) \\
2 \cdot 22(1.80-2 \cdot 74)\end{array}$ & $\begin{array}{l}1.47(1 \cdot 12-1.92) \\
2.94(2 \cdot 27-3 \cdot 80)\end{array}$ & $\begin{array}{l}0.58(0.44-0.75) \\
2.35(1.89-2 \cdot 92)\end{array}$ \\
\hline 4 & $\begin{array}{l}\text { Sex (male } v \text { female) } \\
\text { Atopy at end of period (per atopic condition) } \\
\text { Prior atopy (per atopic condition) }\end{array}$ & $\begin{array}{l}1.32(1.09-1.61) \\
2.03(1.60-2.58) \\
1.25(0.96-1.65)\end{array}$ & $\begin{array}{l}1.47(1.12-1.92) \\
2.54(1.86-3 \cdot 46) \\
1.30(0.97-1.75)\end{array}$ & $\begin{array}{l}0.57(0.44-0 \cdot 74) \\
2 \cdot 17(1 \cdot 70-2 \cdot 78) \\
1 \cdot 20(0.93-1.54)\end{array}$ \\
\hline
\end{tabular}

$\star^{\star}$ The odds ratio for incidence at $0-7$ years (male $v$ female) based on all available information is $1 \cdot 32(1 \cdot 20-1 \cdot 43)$

Table 6 Incidence of asthma or wheezy bronchitis during each study period by number of atopic conditions before the study period and number of atopic conditions reported in the past year at the end of each study period

\begin{tabular}{|c|c|c|c|c|c|c|c|c|c|c|}
\hline \multirow{2}{*}{$\begin{array}{l}\text { Prior atopic } \\
\text { diseases }\end{array}$} & \multirow{2}{*}{$\begin{array}{l}\text { Atopic diseases } \\
\text { in the past year } \\
\text { at end of period }\end{array}$} & \multicolumn{3}{|c|}{ Age 8-11 } & \multicolumn{3}{|c|}{ Age 12-16 } & \multicolumn{3}{|c|}{ Age 17-23 } \\
\hline & & $\%$ & No & Population & $\%$ & No & Population & $\%$ & No & Population \\
\hline None & $\begin{array}{l}\text { None } \\
\text { One } \\
\text { Both }\end{array}$ & $\begin{array}{r}3 \cdot 9 \\
7 \cdot 7 \\
21 \cdot 4\end{array}$ & $\begin{array}{r}320 \\
40 \\
6\end{array}$ & $\begin{array}{r}8185 \\
520 \\
28\end{array}$ & $\begin{array}{r}2 \cdot 8 \\
7 \cdot 6 \\
50 \cdot 0\end{array}$ & $\begin{array}{r}144 \\
27 \\
2\end{array}$ & $\begin{array}{r}5123 \\
356 \\
4\end{array}$ & $\begin{array}{r}3.9 \\
9 \cdot 8 \\
25 \cdot 0\end{array}$ & $\begin{array}{r}144 \\
40 \\
6\end{array}$ & $\begin{array}{r}3660 \\
409 \\
24\end{array}$ \\
\hline One & $\begin{array}{l}\text { None } \\
\text { One } \\
\text { Both }\end{array}$ & $\begin{array}{r}5 \cdot 5 \\
8 \cdot 1 \\
13 \cdot 6\end{array}$ & $\begin{array}{r}28 \\
26 \\
3\end{array}$ & $\begin{array}{r}512 \\
321 \\
22\end{array}$ & $\begin{array}{l}3 \cdot 6 \\
7 \cdot 7 \\
5 \cdot 6\end{array}$ & $\begin{array}{r}18 \\
27 \\
1\end{array}$ & $\begin{array}{r}498 \\
349 \\
18\end{array}$ & $\begin{array}{r}5 \cdot 5 \\
9 \cdot 2 \\
15 \cdot 4\end{array}$ & $\begin{array}{r}28 \\
36 \\
4\end{array}$ & $\begin{array}{r}507 \\
390 \\
26\end{array}$ \\
\hline Both & $\begin{array}{l}\text { None } \\
\text { One } \\
\text { Both }\end{array}$ & $\begin{array}{r}9 \cdot 1 \\
7 \cdot 7 \\
31 \cdot 3\end{array}$ & $\begin{array}{l}1 \\
2 \\
5\end{array}$ & $\begin{array}{l}11 \\
26 \\
16\end{array}$ & $\begin{array}{r}4 \cdot 8 \\
17 \cdot 0 \\
23 \cdot 1\end{array}$ & $\begin{array}{l}1 \\
9 \\
3\end{array}$ & $\begin{array}{l}21 \\
53 \\
13\end{array}$ & $\begin{array}{l}10 \cdot 0 \\
11 \cdot 1 \\
20 \cdot 0\end{array}$ & $\begin{array}{l}3 \\
6 \\
4\end{array}$ & $\begin{array}{l}30 \\
54 \\
20\end{array}$ \\
\hline All subjects & & 4.5 & 431 & 9614 & $3 \cdot 6$ & 232 & 6435 & $5 \cdot 3$ & 271 & 5120 \\
\hline
\end{tabular}

asthma incidence and there was a graded relationship with the highest incidence among those reporting both eczema and hay fever at the end of the study period. At ages 8 to 11 years and 17 to 23 years, the effects of eczema and hay fever after adjustment for sex were not significantly different from each other $\left(\chi^{2}=1 \cdot 23\right.$ and $2 \cdot 44$ respectively, $\left.\mathrm{df}=1\right)$. Between 12 and 16 years of age there was some evidence that hay fever was more strongly related than was eczema to incident asthma or wheezy bronchitis $\left(\chi^{2}=4 \cdot 46, \mathrm{df}=1\right)$. The risk among those reporting both atopic diseases was close to that predicted from their combined effects $\left(\chi^{2}=1 \cdot 40,0.09\right.$, and 0.03 for ages 8 to 11 years, 12 to 16 years, and 17 to 23 years respectively, $\mathrm{df}=1$ ). A single term, equivalent to that used for prior atopy, was therefore used to provide a simplified description of the data (table 5).

\section{INDEPENDENT EFFECTS OF PRIOR AND} SUBSEQUENT ATOPY

Table 6 shows the incidence of asthma or wheezy bronchitis for each study period by the number of atopic diseases reported before the study period and the number reported in the past year at the end of the study period. The results for each study period were similar, with atopy at the end of the study period exerting the stronger influence. After adjustment for the number of atopic conditions reported at the end of the study period, the effect of the number of prior atopic conditions did not approach conventional levels of significance in any of these models $\left(\chi^{2}=2 \cdot 57,2 \cdot 89\right.$, and 1.93 at ages 8 to 11 years, 12 to 16 years and 17 to 23 years respectively, $\mathrm{df}=1$ ) (table 5 ).

\section{Discussion}

In this paper we have concentrated on the incidence of asthma or wheezy bronchitis because it is a fundamental indicator of disease occurrence about which we have little direct evidence. To obtain incidence data directly requires the follow up of a large cohort of healthy individuals over a long time, but the very nature of such a study leads to various problems that may affect the validity of the data. Firstly, such a study is unlikely to be mounted to investigate asthma alone and in the case of the National Child Development Study the health aspects were in fact a minor part of an essentially social and educational study. Thus the measurements of asthma were minimal and were not designed or timed with the needs of epidemiologists in mind. In particular, the wording of the questions varied from sweep to sweep and could have led to underascertainment of asthma by excluding wheezy subjects without "asthma" and whose wheezing was not associated with "bronchitis." It is reassuring that the prevalence estimates obtained were similar to those obtained in other studies at corresponding points of time. ${ }^{4}$ Despite these 
possible deficiencies, we believe that there are sufficient data from which to construct a valuable picture of the incidence of asthma and wheezing illness from birth to 23 years of age.

The second problem, and one that is inherent in any multiple follow up study, is that the incomplete response rates at each sweep, though individually acceptable, tend to accumulate when the data are linked to reduce the overall response even further. Comparison of 12 month period prevalence estimates in those with linked data with those for all subjects seen at any one sweep showed only small differences (up to $5 \%$ in relative terms). Factors associated with non-response at each sweep up to 16 years of age have been exhaustively analysed by Fogelman. ${ }^{5}$ Not surprisingly, the strongest influence was social class. We have previously shown, however, that social class is not a predictor of asthma incidence up to 16 years of age and it is therefore unlikely that response bias will have affected measures of incidence. More importantly, it is difficult to see how factors associated with non-response could have biased our analyses of the effects of atopy and sex on asthma. The strengths of the National Child Development Study should also be emphasised. These include its large sample size and national coverage.

The observation that incidence is highest in early childhood is consistent with studies reporting the age at onset among prevalent cases. ${ }^{6}$ However, such estimates could be biased towards those continuing to have wheeze. At the age of 16 years parents of the cohort were asked about the age at onset of their child's asthma; the pattern of age at onset reported retrospectively in this way corresponded closely to the pattern derived from the linked data. Nevertheless, comparison of the reported lifetime prevalence at each sweep (table 1) with the cumulative estimates (table 2) clearly demonstrates the unreliability of prevalence surveys for ascertaining the proportion of subjects with a past history of wheeze. For example, at 16 years the estimate of lifetime prevalence based on parental recall was $11.5 \%$, whereas that obtained by using cumulative data was $24 \cdot 5 \%$.

The incidence of asthma or wheezy bronchitis during the 11 to 16 and 17 to 23 year study periods $(0 \cdot 7-0.8 \%$ per year) compares with the figure of $0.6 \%$ per year between 7 and 20 years observed by Giles et al among a smaller cohort in Tasmania. ${ }^{7}$ It is also remarkably similar to a figure of $0.6 \%$ per year reported for physician diagnosed asthma in a cohort of 770 children aged between 7 and 23 years in the USA ${ }^{8}$ The cumulative incidence of about $30 \%$ is similar to that obtained by studies of general practice records. ${ }^{9-11}$ The only incidence study of comparable size to the National Child Development Study is a ten year follow up of the US National Health and Nutrition Examination Survey cohort of 14404 subjects, but this involved only adults and used physician diagnosed asthma as the defining criterion. ${ }^{12}$ One observation from this US study was that although the prevalence was similar in males and females incidence was higher in females. This pattern is seen at the end of the observation period in the National Child Development Study and emphasises the added contribution of incidence data to understanding the epidemiology of asthma.

A male excess is usually found in the prevalence of childhood asthma, but surprisingly this increased rather than decreased up to 16 years of age; between 16 and 23 years there was a marked sex reversal. This crossover is also seen in hospital admission and mortality data for England and Wales. The net effect of these patterns was that by the age of 23 years the two sexes had experienced almost the same cumulative incidence. The reasons for these sex effects are unknown. We have previously shown that incidence of childhood asthma to 16 years is not affected by the age at onset of menarche or puberty, ${ }^{1}$ which suggests that the explanation is not related to hormonal changes occurring at that time. Perhaps, as with some other developmental phenomena, the development of atopy varies between the sexes in early childhood but females eventually catch up. Another possibility is that from the age of about 16 years girls begin to experience a different exposure to certain allergens and irritants.

The cohort approach has major advantages in examining the influence of prior risk factors such as atopy because it avoids the recall bias inherent in any cross sectional approach. It does not, however, avoid the possibility that prior atopy might have biased the way in which subsequent respiratory symptoms were interpreted, labelled and reported. In our study, the inclusion of children with episodes labelled as wheezy bronchitis, as well as those diagnosed as asthma, reduced the opportunity for such bias.

The effect of other atopic disease on the incidence of asthma was independent of sex and a good fit to the data was obtained by modelling in terms of the number of atopic conditions. However, with relatively small numbers of incident events, we lack the power to discriminate risks in some subgroups (especially in those with both eczema and hay fever).

The effect of prior atopy on the incidence of asthma or wheezy bronchitis is useful for clinical prediction but seems to be almost entirely "explained" by its ability also to predict atopic disease present at the end of follow up. It may be that the truly influential variable is the degree of atopy active at the time of asthma incidence; this could explain the weak and statistically insignificant independent effect of prior atopy in the multivariate models in table 5, since atopic activity in the earlier part of each study period may be more closely related to prior atopy than to atopy at the end of the period.

Eczema was as strongly related to the incidence of asthma as was hay fever. This suggests that the association between atopic activity and the incidence of asthma is not due to inhaled precipitants such as aeroallergens, but that it is the degree of endogenous susceptibility to all forms of atopic disease that is of biological importance in the development of asthma during childhood and adolescence. We are currently examining the association be- 
tween the incidence of asthma and social and environmental variables in the National Child Developent Study dataset. This analysis will take into account atopic disease as a possible intermediate factor or effect modifier.

We thank Philip Sedgwick and Sean McGuigan for their help with earlier analyses, the ESRC Data Archive for supplying the with earlier analyses, the ESRC Data Archive for supplying the
data, and Peter Shepherd of City University for facilitating links with the National Child Development Study.

1 Anderson HR, Bland JM, Patel S, Patel S, Peckham C. The natural history of asthma in childhood. $J$ Epidemiol Community Health 1986;40:121-9.

2 Williams $\mathrm{H}, \mathrm{McNicol} \mathrm{KN}$. Prevalence, natural history, and relationship of wheezy bronchitis and asthma in children. An epidemiological study. BMJ 1969;4:7-11.

3 SAS Insitute. SAS user's guide. Basics; Statistics. Cary, North Carolina: SAS Insitute, 1985.

4 Anderson HR. Is the prevalence of asthma changing? Arch
Dis Child 1989;64:172-5.

5 Fogelman K. Britain's sixteen-year-olds. London: National Children's Bureau, 1976.

6 Gregg I. Epidemiological aspects. In: Clark TJH, Godfrey S, eds. Asthma. London: Chapman and Hall Medical, 1983:242-78.

7 Giles G, Lickiss N, Gibson H, Shaw K. Respiratory symptoms in Tasmanian adolescents: a follow up of the 1961 birth cohort. Aust NZ J Med 1984;14:631-7.

8 Sherman CB, Tosteson TD, Tager IB, Speizer FE, Weiss ST. Early childhood predictors of asthma. Am J Epidemiol 1990;132:83-95.

9 Goodall JF. The natural history of common respiratory infection in children and some principles in its maninfection in children. J $R$ Coll Gen Pract agement III.

10 Fry J. "Acute wheezy chests": clinical patterns and natural history. BMJ 1961;i:227-32.

11 Strachan DP. The prevalence and natural history of wheezing in early childhood. $J R$ Coll Gen Pract 1985;35:182-4.

12 McWhorter WP, Polis MA, Kaslow RA. Occurrence, predictors, and consequences of adult asthma in NHANESI and follow-up survey. Am Rev Respir Dis 1989;139:721-4. 